\title{
Modeling and Forecasting of Ghana's Inflation Volatility
}

\author{
Abdul-Karim Iddrisu, Dominic Otoo, Iddrisu Wahab Abdul, Sylvia Ankamah \\ Department of Mathematics and Statistics, University of Energy and Natural Resources, Sunyani, Ghana \\ Email: karim@aims.ac.za
}

How to cite this paper: Iddrisu, A.-K., Otoo, D., Abdul, I.W. and Ankamah, S. (2019) Modeling and Forecasting of Ghana's Inflation Volatility. American Journal of Industrial and Business Management, 9, 930-949.

https://doi.org/10.4236/ajibm.2019.94064

Received: March 4, 2019

Accepted: April 23, 2019

Published: April 26, 2019

Copyright $\odot 2019$ by author(s) and Scientific Research Publishing Inc. This work is licensed under the Creative Commons Attribution International License (CC BY 4.0).

http://creativecommons.org/licenses/by/4.0/

\begin{abstract}
In this paper, we assessed volatility of Ghana's inflation rates for 2000 to 2018 using the auto-regressive conditionally heteroskedasticity $(\mathrm{ARCH})$, generalized ARCH (GARCH), and the exponential GARCH (EGARCH) models. The inflation data were obtained from the Ghana Statistical Service (GSS). The proposed model should be able to provide projections of inflation volatility from 2019 and beyond. The results showed that higher order models are required to properly explain Ghana's inflation volatility and the EGARCH(12, $1)$ is the best fitting model for the data. The $\operatorname{EGARCH}(12,1)$ model is robust to model and forecast volatility of inflation rates. Also, the results suggest that we are forecasting increasing volatility and there is increasing trend in general prices of goods and services for 2018 and beyond. The forecasts figures revealed that Ghana's economy is likely to be unstable in 2018 and 2019. This study therefore recommends that policy makers and industry players need to put in place stringent monetary and fiscal policies that would put the anticipated increase in inflation under control. The models were implemented using R software.
\end{abstract}

\section{Keywords}

Exponential Generalized Auto-Regressive Conditionally Heteroskedasticity, Generalized Auto-Regressive Conditional Heteroskedasticity Model, Macroeconomic

\section{Introduction}

Inflation is an economic indicator that measures the relative changes in the prices of commodities and services and also measures the persistent increase in the level of consumer prices or persistent decline in the purchasing power of money [1]. Inflation can be caused by either too much money in circulation in 
the country or too few goods offered for sale [2]. This economic indicator has direct effect on the state of the economy. In other to devise better policies to control the inflation rates, it is necessary to know the pattern of inflation in the country. Inflation is an important economic indicator that the government, politicians, economists, and other stake holders especially those in African continent including Ghana use when debating on the state of the economy.

In recent years, inflation has become one of the major economic challenges facing most countries in the world [3]. In Ghana, both the government and opposition parties focus is on achieving single digit inflation when debating on the state of the economy. Most often opposition party doubts figures suggesting that the economy is stable with consistent single digit inflation since they are of the belief that these figures do not represent the true state of the economy. Both the government and the opposition parties are concerned about the inflation rates (which represent the level of price goods and services) in the country which affects all sectors of the economy [4].

It is known that the traditional time series models assume that the conditional variance is constant. However, most economic and financial time series data are heteroskedastic (non-constant variance) in nature. This means that time series models that assume constant variance for the data are likely under-performed and produce bias statistical inferences when applied to non-constant variance time series data. There is therefore the need to build times series models to accommodate data with non-constant variance [5]. The auto-regressive conditionally heteroskedasticity (ARCH) model [6] [7] [8] and its extension to the generalized auto-regressive conditionally heteroskedasticity (GARCH) model [9] and exponential generalized auto-regressive conditionally heteroskedasticity (EGARCH) model [10] have been proposed to model the non-constant volatility of such series. To ensure the variance are positive, the GARCH model imposed restrictions on the parameters whereas the EGARCH model does not require restrictions on the parameters to assume a positive variance [8] [10].

Various authors, for example, [11] [12] have made attempt to model/study inflation in Ghana. However, they used models that did not account for the conditional heteroskedasticity on the Ghana's inflation data [4]. David [3] noted that it is statistically inefficient and logically inconsistent to model volatility using models that assume that the variance is constant when the resulting series progress over time.

Inflation in various countries has been studied/modeled by various authors [13] [14] [15] [16]. In this paper, we seek to model Ghana's inflation using the GARCH [9] and EGARCH [10] approaches. Results from these models are compared with that of the ARCH model. For detailed and clear information on ARCH, GARCH, and EGARCH models, see Bera and Higgins [8].

The rest of the article is organized as follows. In Section 2, we give an overview of the Ghana's inflation and then an exploratory analysis of the inflation data used in Section 3. We discuss the ARCH, GARCH, and EGARCH models in Section 4. We then implement these models to the inflation data in Section 5 and 
give summary remarks in Section 6.

\section{Overview of Ghana's Inflation}

In this section we present a brief history of Ghana's inflation rates from 1965 to 2017. Figure 1 presents time series plot of yearly inflation rates from 1965 to 2017. It can be observed that Ghana recorded a negative inflation rate $(-8.4 \%)$ in 1967 and recorded a rise generally from $9.6 \%$ in 1971 to $116.5 \%$ in 1977 . A very high inflation volatility is observed between the year 1974 and 1985 with the highest inflation rate of $122.25 \%$ in 1984 followed by $116.5 \%$ in the years 1981 and 1977. Inflation volatility, generally, decreases from 1985 to 2017. Inflation rate of $9.6 \%$ in April 2018 edged up to $10 \%$ in June of 2018 from $9.8 \%$ in May 2018. Transportation was the only category showing a higher inflation rate. The inflation rate in Ghana fell to $9.6 \%$ in July of 2018 from 10 percent in June 2018. It was the lowest inflation rate since April which is due to a slowdown in non-food prices. The annual inflation rate in Ghana rose up to $9.9 \%$ in August of 2018 from $9.6 \%$ in July, as both food and non-food inflation rose. The annual inflation rate in Ghana fell to 9.3\% in November 2018 from 9.5\% in September. This inflation figure remains the lowest inflation since December 2012. Inflation volatility remains relatively low from 1997 to 2017 . However, there is the need to understand inflation volatility behavior and then put measures in place to reduce negative effect of unexpected shocks that may arise dues to inflation uncertainties. In this paper, we model the monthly inflation rates from 2000 to 2017 and then provide forecast inflation rates for 2018 in order to assess the validity and prediction power of the proposed model for the Ghana's inflation volatility.

\section{Description of the Inflation for $\mathbf{2 0 0 0 - 2 0 1 8}$}

In this section, we provide exploratory assessment of the characteristics of the inflation data we obtained from the Ghana Statistical Service (GSS). Our focus is to study/investigate volatility of inflation rates for 2000-2018 and thereafter, suggest a best fitting model for the data. All the analyses in this paper are analyzed using R software [17] [18] [19]. Figure 2 displays the time series plot for

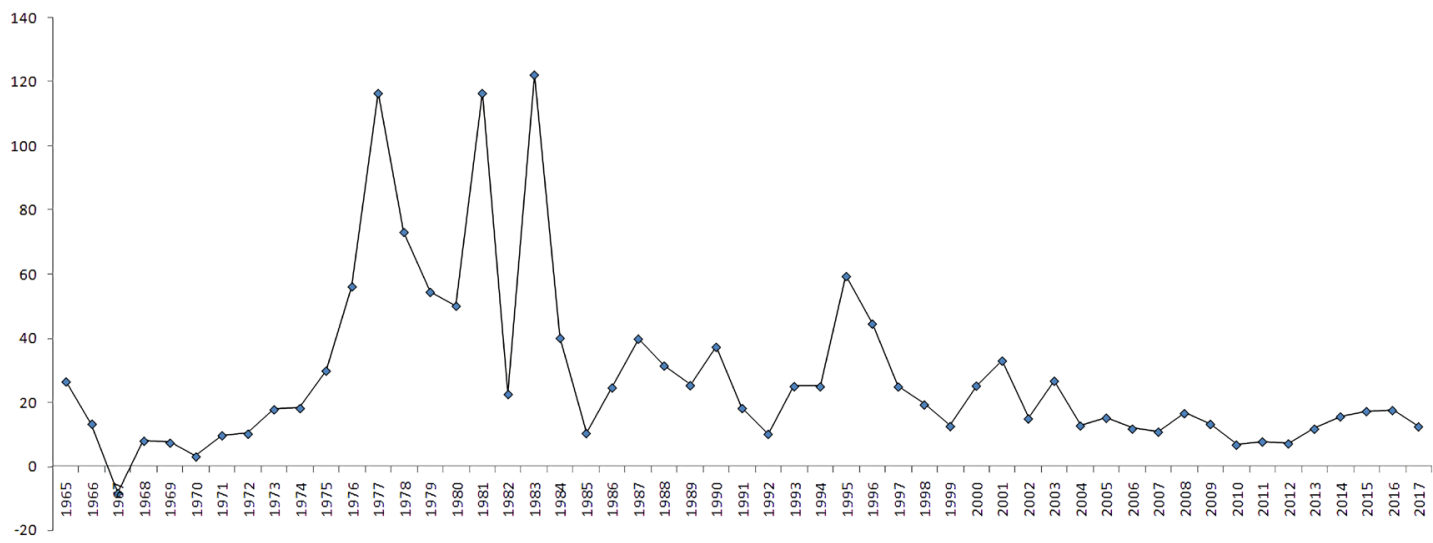

Figure 1. Time series plot of yearly inflation rates from 1965 to 2017. 


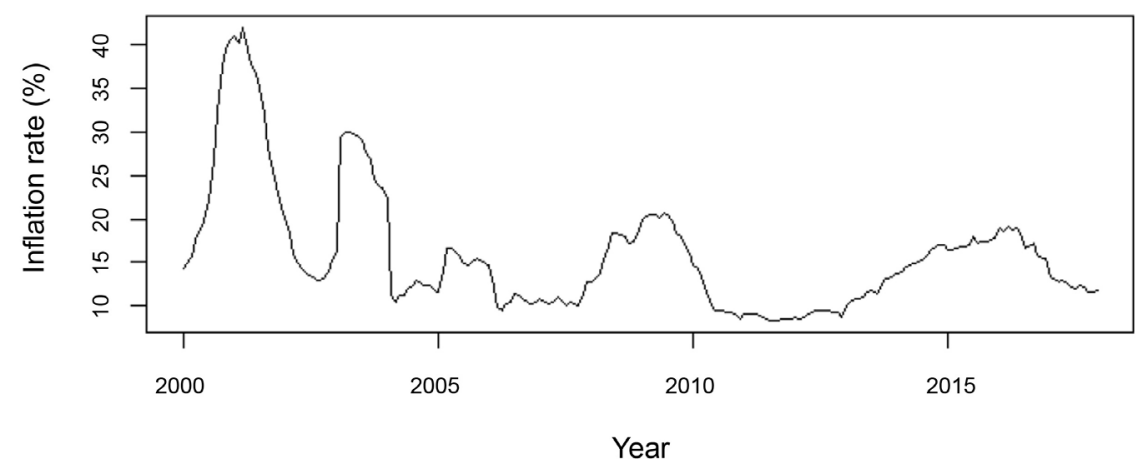

Figure 2. Time series plot of inflation rates for 2000 to 2017 .

inflation rates for 2000 to 2017. The inflation rates plot exhibits downward trend which fluctuate over the study period. These fluctuations in the inflation rates give an indication that the mean as well as the variance of the inflation rates are not constant over time.

We performed a normality test on the mean and variance using the Anderson-Darling Normality Test [20] [21] at 5\% level of significance. The normality test results revealed a very small $p$-value $(<0.001)$ which gives an indication that there is smaller chance that we are looking at data from a normal distribution and that the data are non-stationary. Because of the non-stationarity of the data, we applied the unit root test (Augmented Dickey Fuller Test) [22] [23] [24], on the inflation data, in order to further investigate for non-stationarity of the inflation time series data. The result from the Augmented Dickey-Fuller (ADF) $t$-test suggests that the data are non stationary and does need other methods such as differencing to achieve stationarity. This means that a unit root exist and as a result the data are non-stationary. These results on non-stationarity of the inflation data are evident from Figure 2.

In order to achieve stationarity in the inflation rates time series data, we carried out logarithm and differencing transformation. Achieving stationarity is important because the models that are used in this paper assume that the data are stationarity. This means that there is the need to achieve stationarity, in the inflation time series data, in order to produce valid statistical inferences. Figure 3 displays the time series plot of the logarithm of inflation rates from January 2000 to December 2017. However, the logarithm transformation approach could not do much in terms achieving stationarity since the time series plot appears fluctuating after the transformation of the inflation rates. This implies that the mean and variance are not constant over the study period. This means that the inflation time series data cannot be stationarized using the logarithm. We note that the logarithmic transformation is often useful for series that must be greater than zero and that grow exponentially. However, this is not case for the Ghana's 2000-2017 inflation rates since series do not grow exponentially over time. That is, the series does not grow exponentially and the variability of the series does not increase over time. This offers an explanation to inability of the logarithm 


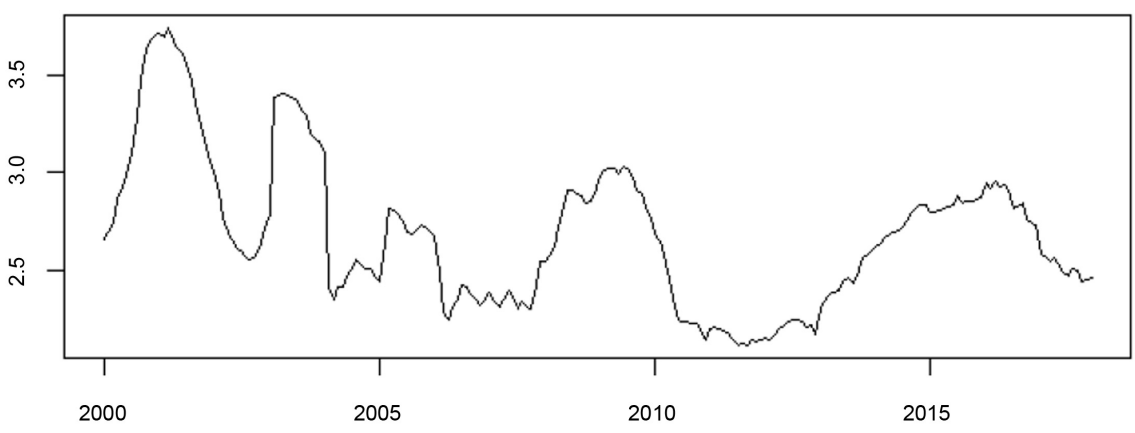

Figure 3. Time series plot of logarithm of monthly inflation rate in Ghana from 2000 to 2017.

transformation to achieve stationarity. Figure 4 displays the plot of the first ordinary difference [25] of the logarithm of the monthly inflation rates.

In Figure 4, the time series plot appears to be stable after this transformation. This plot suggests that the mean and variance are now constant after using the differencing approach. This gives an indication that there is stationarity in the first ordinary difference monthly rate of inflation series. We performed a confirmatory test on stationarity by using the Augmented Dickey Fuller unit root test on the first and second difference of the inflation rates. The test results $(p$-value $=0.01<0.05)$ suggest that the series is stationary enough to do any kind of time series modeling.

We now investigate for the presence of auto-correlation in the original, logarithm and differencing transformation datasets. It can be observed in Figure 5 that the auto-correlation function (ACF) charts for the original data (top panel) and the logarithm transformed data (middle panel) decays are very slow from lag 0.1 to 1.0 and fast after the lag 1 . The ACF curves are significant from lag 0.1 to lag 1. This means that the data are not stationary. However, the ACF charts (bottom panel) for the differenced inflation rates decays very fast with only two significant lags. This gives an indication that the data are stationary.

Also, it can be observed in Figure 6 that the partial auto-correlation function (PACF) chats, for the original data (top panel) and the logarithm transformed data (middle panel), show 3 significant lags each, whereas PACF curve for the differenced inflation rates shows only one significant lag. Given these exploratory analyses, we can conclude that one can achieve stationarity in the Ghana's 2000-2018 inflation time series data using the ordinary first difference approach.

We recall that Figure 2 shows that there is some level heteroskedasticity (changing variance over time) in the monthly rate of inflation series, and a formal test for heteroskedasticity was carried out to confirm the presence of heteroskedasticity (ARCH effect). We use the Ljung-Box test statistic to test for $\mathrm{ARCH}$ effect, in the differenced data. We used the Box.test function and the results showed that there is presence of ARCH effect (since the $p$-value is less than 0.05 level of significance). We also used the garchFit function in fGarch package to confirm the presence of ARCH effect. The results show a significant evidence 


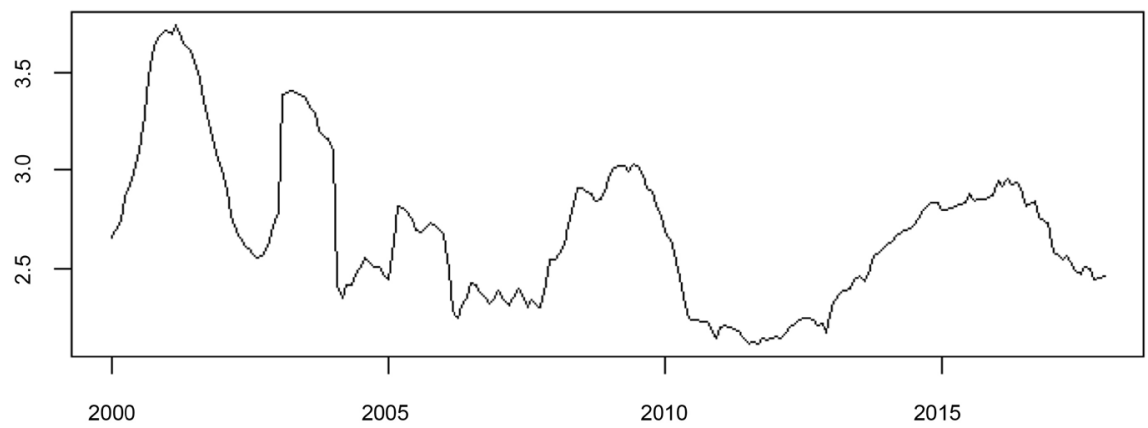

Figure 4. Time series plot of the first difference of the monthly rates of inflation for 2000-2017.
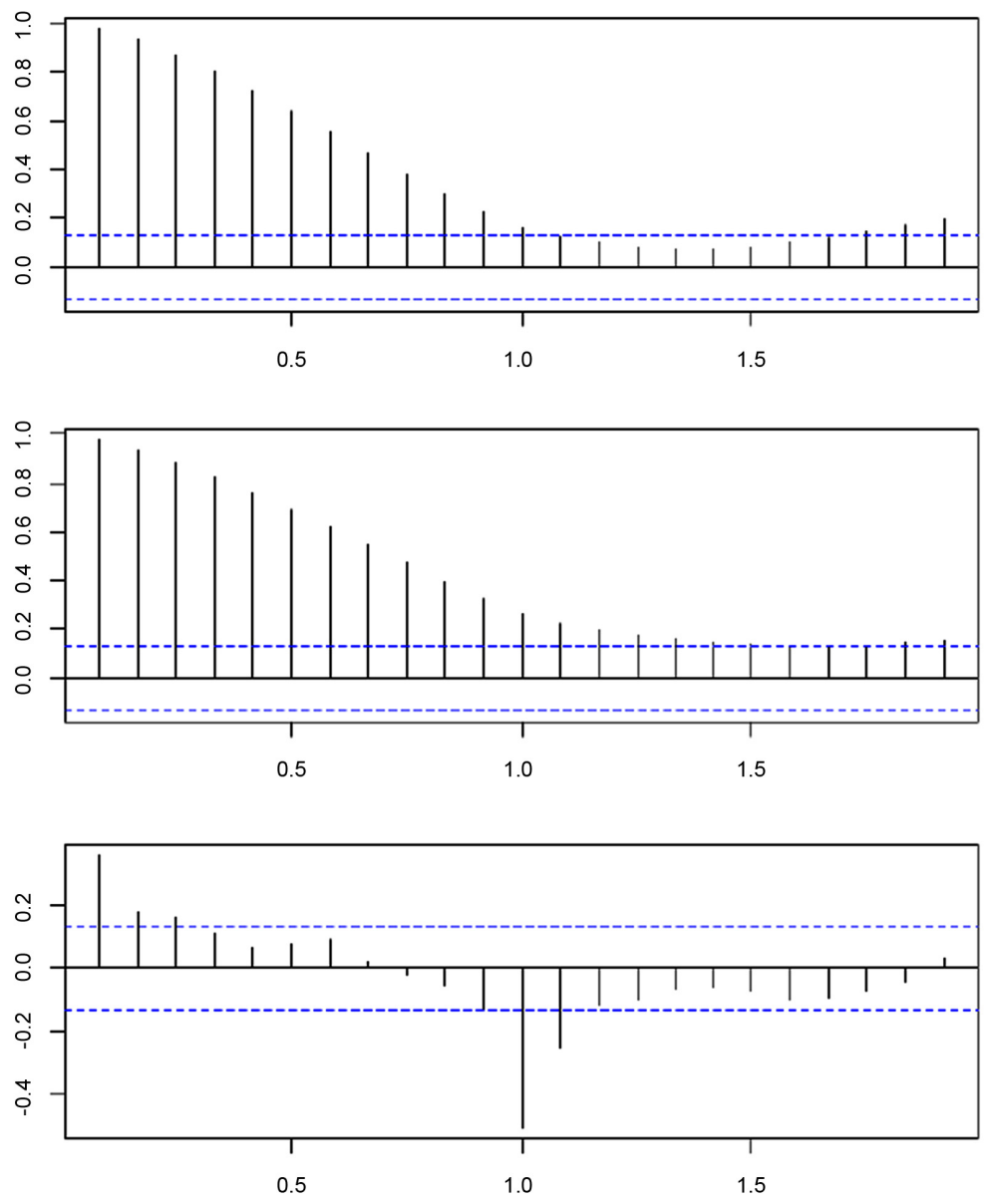

Figure 5. AFC for the original data (first panel), logarithm transformed data (second panel), and the differenced data (third panel).

of heteroskedasticity (ARCH effects) although it has been reduced as compared to the case of the original monthly rate of inflation series.

From the fore going analysis, it can be concluded that the first difference monthly rates of inflation satisfy all the data assumption or characteristics for a volatility model such as the ARCH-family models. Hence in subsequent analyses, the first differenced monthly rates of inflation would be used or considered. 

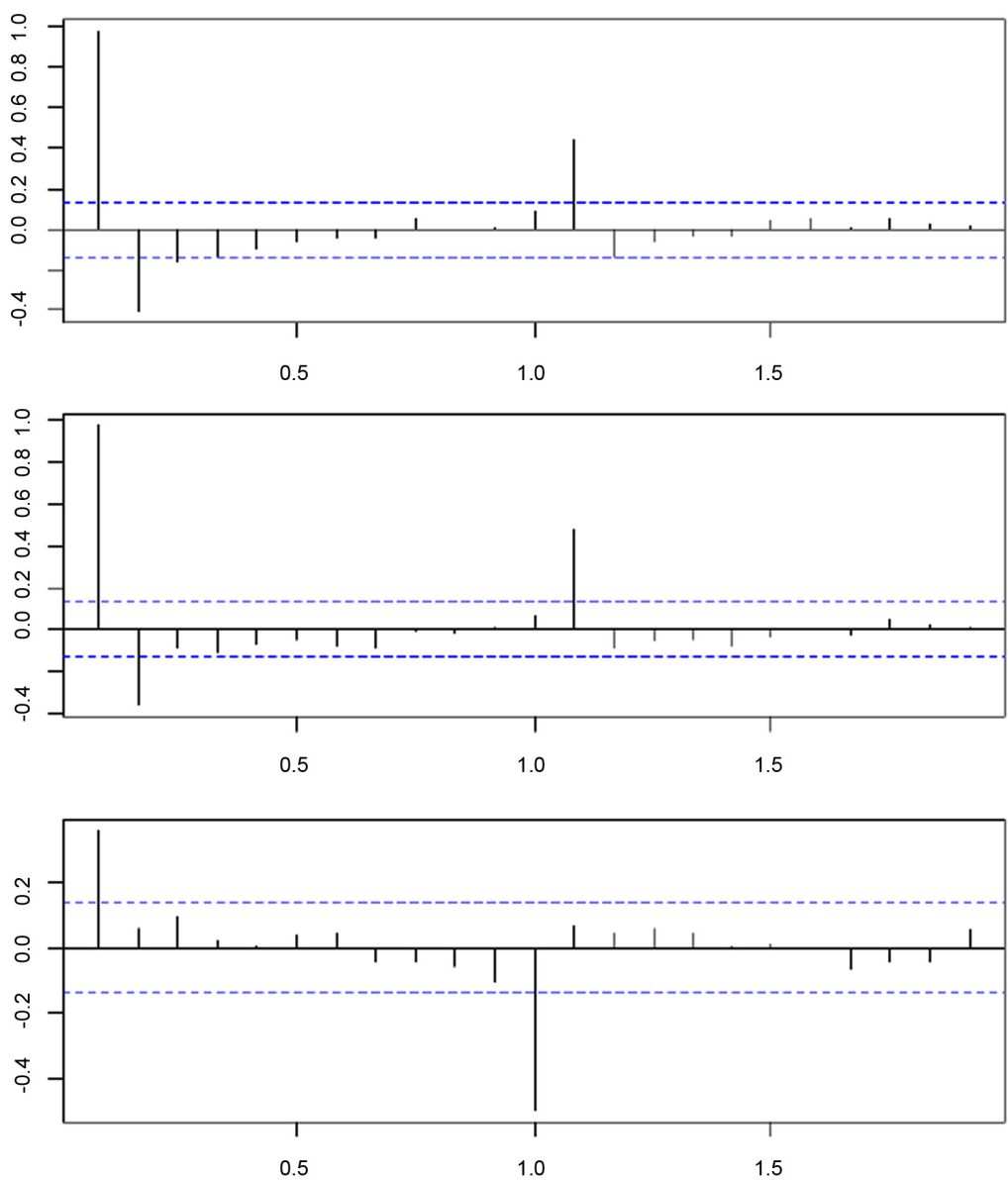

Figure 6. PAFC for the original data (first panel), logarithm transformed data (second panel), and the differenced data (third panel).

\section{Models for Modeling Volatility in Data}

This section presents notations and concepts of the ARCH, GARCH, and EGARCH ARCH-family models for volatility in times series data.

\subsection{Auto-Regressive Conditional Heteroskedasticity (ARCH) Model}

The ARCH models [6] provide a framework for modeling volatility in time series data. Detailed information on ARCH model can be found in [8] paper. There are various ways to define the $\mathrm{ARCH}$ process depending on the context [8]. In this paper, we defined the ARCH process in terms of the distribution of the errors of a dynamic linear regression model. Let $y_{t}$ denotes the dependent variable which is assumed to be generated by

$$
y_{t}=\boldsymbol{x}_{t}^{\prime} \boldsymbol{\delta}+\epsilon_{t}, t=1,2, \cdots, T,
$$

where $\boldsymbol{x}$ is a $p \times 1$ vector of exogenous variables, which may include lagged values of the dependent variable, and $\delta$ is a $p \times 1$ vector of regression parameter estimates. The ARCH model characterizes the distribution of the stochastic error term $\epsilon_{t}$ conditional on the realized values of the set of variables $\psi_{t-1}=\left\{y_{t-1}, x_{t-1}, y_{t-2}, x_{t-1}, \cdots\right\}$. The original Engle's [6] $\operatorname{ARCH}(q)$ model, with 
order $q$, assumes that

$$
\epsilon_{t} \mid \psi_{t-1} \sim N\left(0, h_{t}\right), \quad \text { where } h_{t}=\alpha_{0}+\alpha_{1} \epsilon_{t-1}^{2}+\alpha_{2} \epsilon_{t-2}^{2}+\cdots+\alpha_{q} \epsilon_{t-q}^{2},
$$

with constrains $\alpha_{0}>0$ and $\alpha_{i} \geq 0, i=1,2, \cdots, q$ in order to ensure that the conditional variance is positive. Since $\epsilon_{t-1}=y_{t-1}-\boldsymbol{x}_{t-1}^{\prime} \boldsymbol{\delta}, i=1,2, \cdots, q, h_{t}$ is obviously a function of the elements of $\psi_{t-1}$.

It is important to note that distinguishing feature of the model (2) is not only that the conditional variance $h_{t}$ is a function of the conditioning set $\psi_{t-1}$, but rather it is the particular functional form that is specified [8]. Episodes of volatility are generally characterized of the clustering of large shocks to the dependent variable $y_{t}$. The conditional variance function $h_{t}(2)$ is formulated to take into account this situation. We note that in a regression model a large shock is represented by a large deviation of the dependent variable $y_{t}$ from its mean $\boldsymbol{x}_{t}^{\prime} \boldsymbol{\delta}$. This means that a large shock is represented by a large positive or negative value of the error term $\epsilon_{t}$. It has been established that [8] the variance of the current error term $\epsilon_{t}$, conditional on the realized values of the lagged errors $\epsilon_{t-i}$, is an increasing function of the magnitude of the lagged error, regardless of their signs. This means that large errors of either sign tend to be accompanied by large error of either sign and also, small errors of either sign tend to be accompanied by small error of either sign [8]. The order of the lag $q$ determines how long a shock remains in conditioning variance of the subsequent errors. The longer the lag $q$ the longer the episodes of volatility will tend to be [8]. See further information on $\operatorname{ARCH}(q)$ model in ([8], pp. 309-312).

\subsection{Generalized Auto-Regressive Conditional Heteroskedasticity (GARCH) Model}

The ARCH model was first empirically applied to the relationship between the level and the volatility of inflation [6] [7] [8]. Engle [6] [7] found that a large lag $q$ was required in the conditional variance function $h_{t}$. This requires estimating a large number of parameters subject to the inequality constrains/restriction which is computationally intensive. In order to reduce this computational burden, Engle [6] [7] parameterized the conditional variance function $h_{t}$ as

$$
h_{t}=\alpha_{0}+\alpha_{1} \sum_{i=1}^{q} w_{i} \epsilon_{t-i}^{2}, \text { where the weights } w_{i}=\frac{(q+1)-i}{\frac{1}{2} q(q+1)}
$$

tend to decline linearly over time and constructed in such a way that $\sum_{i=1}^{q} w_{i}=1$. Given this parameterization, a large lag $q$ can be specified and yet only two parameters are required to be estimated in the conditional variance function $h_{t}$ ([6] [7] [8], pp. 312). Despite the fact that linear declining weights are plausible, the formulation impose unnecessary restrictions on the dynamics of the ARCH process ([8], pp. 312).

Bollerslev [9] extended the condition variance function $h_{t}$ (2) to the generalized ARCH (GARCH), which has proven to be useful in empirical research. It is important to acknowledge that Taylor ([8], pp. 312) also independently pro- 
posed the GARCH model. They proposed that the conditional variance $h_{t}$ should be specified as

$$
h_{t}=\alpha_{0}+\alpha_{1} \epsilon_{t-1}^{2}+\alpha_{2} \epsilon_{t-2}^{2}+\cdots+\alpha_{q} \epsilon_{t-q}^{2}+\beta_{1} h_{t-1}+\beta_{2} h_{t-2}+\cdots+\beta_{p} h_{t-p},
$$

where the following inequality constrains are required in order to ensure that the conditional variance $h_{t}$ is strictly positive:

$$
\alpha_{0}>0, \alpha_{i} \geq 0 \text { for } i=1, \cdots, q \text { and } \beta_{j} \geq 0 \text { for } j=1, \cdots, p .
$$

So we say that a GARCH process with order $p$ and $q$ is denoted as $\operatorname{GARCH}(p$, $q)$. The $\operatorname{GARCH}(p, q)$ model consists of three components:

1) $\alpha_{0}$ is the weighted long run variance.

2) $\sum_{i=1}^{q} \alpha_{i} \epsilon_{t-i}^{2}$ is the moving average term, which is the sum of the $m$ previous lags of squared-innovations multiplied by the assigned weight $\alpha_{i}$ for each lagged square innovation.

3) $\sum_{j=1}^{p} \beta_{j} h_{t-j}$ is the auto-regressive term, which is the sum of the $s$ previous lagged variances multiplied by the assigned $\beta_{j}$ for each lagged variance.

It is important to point out that the motivation of the GARCH process can be observed in the expression (3) as the conditional variance $h_{t}$ can be expressed as

$$
h_{t}=\alpha_{0}+\alpha(B) \epsilon_{t}^{2}+\boldsymbol{\beta}(B) h_{t},
$$

where

$$
\alpha(B)=\alpha_{1} B^{1}+\alpha_{2} B^{2}+\cdots+\alpha_{q} B^{q} \text { and } \boldsymbol{\beta}(B)=\beta_{1} B^{1}+\beta_{2} B^{2}+\cdots+\beta_{p} B^{p}
$$

are polynomials in the back-shift operator $B$ ([8], pp. 313). So if the roots of $1-\beta(Z)$ lie outside the unit circle, the condition variance function (3) can be rewritten as

$$
h_{t}=\frac{\alpha_{0}}{1-\beta(1)}+\frac{\boldsymbol{\alpha}(B)}{1-\boldsymbol{\beta}(B)} \epsilon_{t}^{2}=\alpha_{0}^{*}+\sum_{i=1}^{\infty} \xi_{i} \epsilon_{t-1}^{2}
$$

where $\alpha_{0}^{*}=\frac{\alpha_{0}}{1-\beta(1)}$ and the coefficient $\xi_{i}$ is the coefficient of $B^{i}$ in the expansion of $\left[\frac{\alpha(B)}{1-\beta(B)}\right]^{-1}$. The conditional variance function (5) reveals that a $\operatorname{GARCH}(p, q)$ is an infinite order $\mathrm{ARCH}$ process with a rational lag structure imposed on the coefficients [8]. Bera and Higgins [8] pointed out that the generalization of ARCH to GARCH is similar to the generalization of moving average (MA) process to an auto-regressive integrated moving average (ARIMA). The aim is that the GARCH process can parsimoniously represent an $\mathrm{ARCH}$ process.

Bera and Higgins [8] stated that although the restrictions (4) are sufficient to ensure that the conditional variance of a $\operatorname{GARCH}(p, q)$ process is strictly positive, Nelson and Cao [10] showed that a weaker sufficient condition can be found. These authors noted that given the inverted representation of the conditional variance $h_{t}$ in (5), the constrains 


$$
\alpha_{0}^{*}>0 \text { and } \xi_{i} \geq 0, i=1, \cdots, \infty
$$

are sufficient to ensure that the conditional variance is strictly positive. Nelson and Cao expressed $\alpha_{0}^{*}$ and $\xi_{i}$ 's in terms of the original parameters of the GARCH model and showed that the expression (6) does not require all the inequalities in (4) to hold. That is in $\operatorname{GARCH}(1,2)$ process, $\alpha_{0}>0, \alpha_{1} \geq 0, \beta_{1} \geq 0$, and $\beta_{1} \alpha_{1}+\alpha_{2} \geq 0$ are sufficient to ensure that $h_{t}>0$. This means that in $\operatorname{GARCH}(1,2), \alpha_{2}$ may be negative. Nelson and Cao present general results on $\operatorname{GARCH}(1, q)$ and $\operatorname{GARCH}(2, q)$, but stated that a derivation for GARCH process with $p \geq 3$ is difficult. Several empirical studies [26] [27] [28] reported negative coefficients and yet satisfy the conditions for a positive conditional variance based on (6). The authors concluded that the inequalities restrictions (4) should be imposed in the estimation. This is because any violation of these inequalities does not imply that the conditional variance is misplaced ([8], pp. 313).

\subsection{Exponential Generalized Auto-Regressive Conditional Heteroskedasticity (EGARCH) Model}

Since one of the first challenges encountered using the linear ARCH model was that the estimated $\alpha_{i}$ were most often negative, Geweke [29] and Milhoj [30] proposed the log ARCH model

$$
\log \left(h_{t}\right)=\alpha_{0}+\alpha_{1} \log \left(\epsilon_{t-i}^{2}\right)+\cdots+\alpha_{q} \log \left(\epsilon_{t-q}^{2}\right)
$$

in order to avoid negative estimates of $\alpha_{i}$. It can be observed that taking exponential on both sides of the expression (7), the conditional variance becomes

$$
h_{t}=\exp \left(\alpha_{0}+\alpha_{1} \log \left(\epsilon_{t-i}^{2}\right)+\cdots+\alpha_{q} \log \left(\epsilon_{t-q}^{2}\right)\right)
$$

which is strictly positive. This means that no restrictions are required for estimates of $\alpha_{i}$ to ensure that the conditional variance is strictly positive. In order to assess whether the expression (2) or (7) provides best fit of the actual data, Higgins and Bera (1992) suggested the non-linear ARCH (NARCH) model with non-negativity restrictions, but includes linear $\mathrm{ARCH}$ as a special case and log ARCH as a limiting case. Higgins and Bera (1992) concluded that data favored logarithmic ARCH model than the linear ARCH model (also see the $h_{t}$ formulations in Bera and Higgins ([8], pp. 313)).

One potential limitation of the functional form of the $h_{t}$ described above is that this conditional variance is symmetric in the lagged $\epsilon_{t}$ 's. Nelson [10] pointed out that a symmetric conditional variance function is not suitable for modeling the volatility of stocks or returns since it cannot represent leverage effect, which is the negative correlation between volatility and past returns. Nelson suggested that in the general ARCH formulation

$$
h_{t}=h\left(\eta_{t-1}, \eta_{t-2}, \cdots, \eta_{t-q}, h_{t-1}, h_{t-2}, \cdots, h_{t-p}\right),
$$

$h_{t}$ can be viewed as a stochastic process in which $\eta_{t}$ serves as a "forcing variable" for the both the conditional variance and the error term. Nelson nel- 
son1991conditional used the expression (8) to produce the desire dependencies and to avoid non-negativity restriction on the parameter estimates, he maintained the expression (7) and proposed

$$
\begin{aligned}
& \log \left(h_{t}\right)=\alpha_{0}+\sum_{i=1}^{q} \alpha_{i} g\left(\eta_{t-i}\right)+\sum_{i=1}^{p} \beta_{i} \log \left(h_{t-i}\right) ; \\
& g\left(\eta_{t}\right)=\theta \eta_{t}+\gamma\left[\left|\eta_{t}\right|-E\left|\eta_{t}\right|\right] .
\end{aligned}
$$

The conditional variance (9) is known as the exponential GARCH (EGARCH). For detailed information about the properties of the EGARCH model, see Bera and Higgins ([8], pp. 332). That is

1) The conditional variance is pairwise linear in $\eta_{t}$ with slopes $\alpha_{i}(\theta+\gamma)$ when $\eta_{t}$ is positive and $\alpha_{i}(\theta+\gamma)$ when $\eta_{t}$ is negative.

2) The first term in $\log \left(h_{t}\right)$ in the expression (9) allows for the correlation between the error term and future conditional variances. For instance, if $\gamma=0$ and $\theta<0$, then a negative $\eta_{t}$ will result in negative error and the variance process will be positive.

3) The second term in $\log \left(h_{t}\right)$ in the expression (9) produces ARCH effect. Assume that $\gamma>0$ and $\theta=0$. Whenever the absolute magnitude of $\eta_{t}$ exceeds its expected value, the innovation $g\left(\eta_{t}\right)$ is positive. This means that large shocks increase the conditional variance.

\section{Analyses}

In this section, we fitted ACRH, GARCH, and EGARCH models to the inflation data for 2000 to 2017. Candidates models will be fitted to the data in order to determine the besting fitting model for the inflation data.

For the ARCH model, we used the function $\operatorname{garch}()$ in the tseries package. We note that the function $\operatorname{garch}()$ is used for GARCH model fitting. However, function garch() becomes an ARCH model when used with the order argument equal to $c(q>0,0)$. The PACF chart in Figure 6 (bottom left panel) of the squared values has a single spike at lag 1 suggesting an auto-regressive AR(1) model for the squared series. We again note that if the PACF of the squared values suggests $\operatorname{AR}(q)$, then $\operatorname{ARCH}(q)$ may work [6]. Hence, we fitted various candidate $\operatorname{ARCH}(q)$ models with different lags to the differenced inflation data for 2000-2017. The estimates of AICs and log-likelihoods $(-2 \ell)$ of some selected candidate $\operatorname{ARCH}(q)$ models are shown in the first column of Table 1 . Our analyses suggest that the $\operatorname{ARCH}(12)$ model is the best fitting model for the inflation rates data since it has the lowest AIC $(-2.75)$ with the largest $-2 \ell=309.68$ [31]. The auto-correlation function (ACF) and partial auto-correlation function (PACF) charts shown in Figure 7 suggest that there is no significant lag.

On the other hand, various $\operatorname{GARCH}(p, q)$ and $\operatorname{EGARCH}(p, q)$ candidate models were fitted to the differenced inflation data for 2000-2017. The results from these candidate models are respectively shown in columns two and three of Table 1. These results suggest that the $\operatorname{GARCH}(12,1)$ model, with the lowest AIC $=-2.74$ and largest $-2 \ell=309.68$, is the best fitting model for the inflation 
Table 1. Performance of ARCH, GARCH, and EGARCH models.

\begin{tabular}{lcclccccc}
\hline \multicolumn{3}{c}{ ARCH } & \multicolumn{3}{c}{ GARCH } & \multicolumn{3}{c}{$\operatorname{EGARCH}$} \\
\hline $\operatorname{ARCH}(q)$ & AIC & $-2 \ell$ & $\operatorname{GARCH}(p, q)$ & AIC & $-2 \ell$ & $\operatorname{EGARCH}(p, q)$ & AIC & $-2 \ell$ \\
$\operatorname{ARCH}(1)$ & -2.28 & 248.29 & $\operatorname{GARCH}(1,1)$ & -2.33 & 254.12 & $\operatorname{EGARCH}(1,1)$ & -3.12 & 343.22 \\
$\operatorname{ARCH}(2)$ & -2.27 & 247.95 & $\operatorname{GARCH}(1,2)$ & -2.34 & 256.21 & $\operatorname{EGARCH}(1,2)$ & -3.15 & 347.36 \\
$\operatorname{ARCH}(3)$ & -2.26 & 248.33 & $\operatorname{GARCH}(2,1)$ & -2.32 & 254.25 & $\operatorname{EGARCH}(2,1)$ & -3.13 & 346.39 \\
$\operatorname{ARCH}(4)$ & -2.25 & 247.70 & $\operatorname{GARCH}(2,2)$ & -2.33 & 256.21 & $\operatorname{EGARCH}(2,2)$ & -3.14 & 348.02 \\
$\operatorname{ARCH}(12)^{*}$ & -2.75 & 309.68 & $\operatorname{GARCH}(12,1)^{*}$ & -2.74 & 309.68 & $\operatorname{EGARCH}(12,1)^{*}$ & -3.21 & 374.76 \\
\hline
\end{tabular}

*denotes the best candidate model and $-2 \ell$ denotes the log-likelihood.
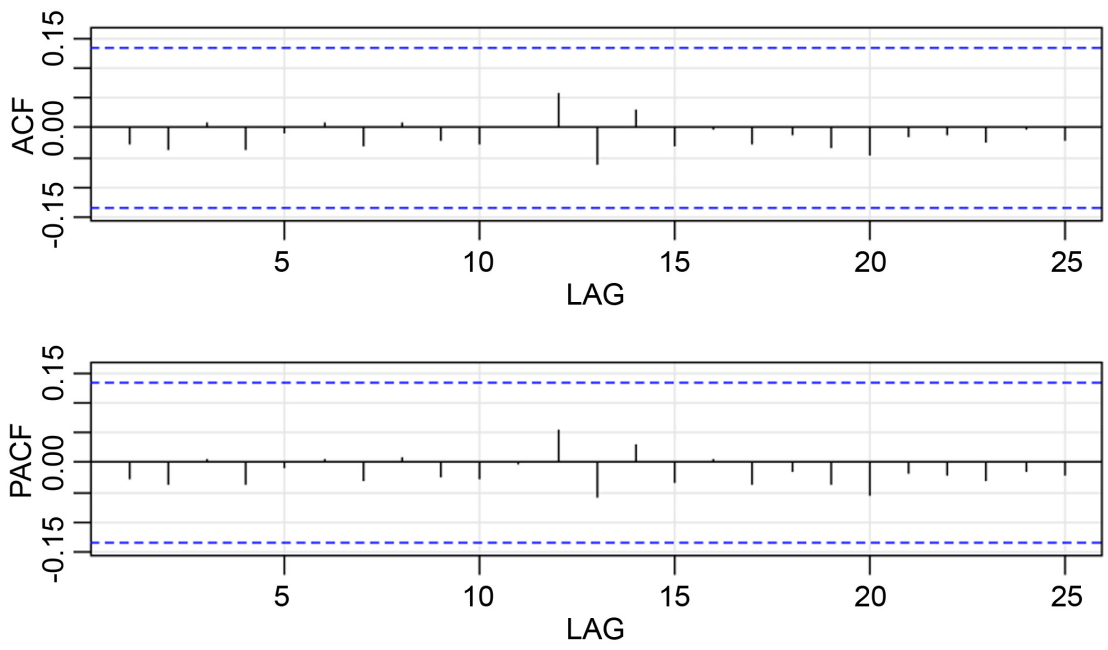

Figure 7. AFC and PACF charts of the square of the standardized residuals for the $\operatorname{ARCH}(12)$ model.

data. It follows that the $\operatorname{EGARCH}(12,1)$ model, with the lowest $\mathrm{AIC}=-3.21$ and largest $-2 \ell=374.76$, is best fitting model. The auto-correlation function charts for the $\operatorname{GARCH}(12,1)$ and $\operatorname{EGARCH}(12,1)$ are shown Figure 8 and Figure 9. It can be observed from these charts that all the bars are within the significance bounds with no significant lag.

Now we present, compare, and contrast results from these best fitting models (ARCH(12), $\operatorname{GARCH}(12,1)$, and $\operatorname{EGARCH}(12,1)$. The parameter estimates from these models are presented in Table 2.

It can be observed that some of the parameter estimates $\alpha_{2}, \alpha_{3}, \alpha_{7}$ and $\alpha_{9}$ and their corresponding standard errors are approximately zeros. The test for $\mathrm{ARCH}$ effect results indicates that there is no $\mathrm{ARCH}$ effect in the $\mathrm{ARCH}$, GARCH, and EGARCH models considered. Because higher order $q=12$ is required to eliminate auto-correlation in the residuals and restrictions imposed on the parameters in the ARCH and GARCH models, there was issue of convergence as some of the diagonals of the matrix of these parameters are negatives. These results confirmed the results from various authors [8] [10] [29] [30] that the estimates from these models are most often negatives. However, these issues 

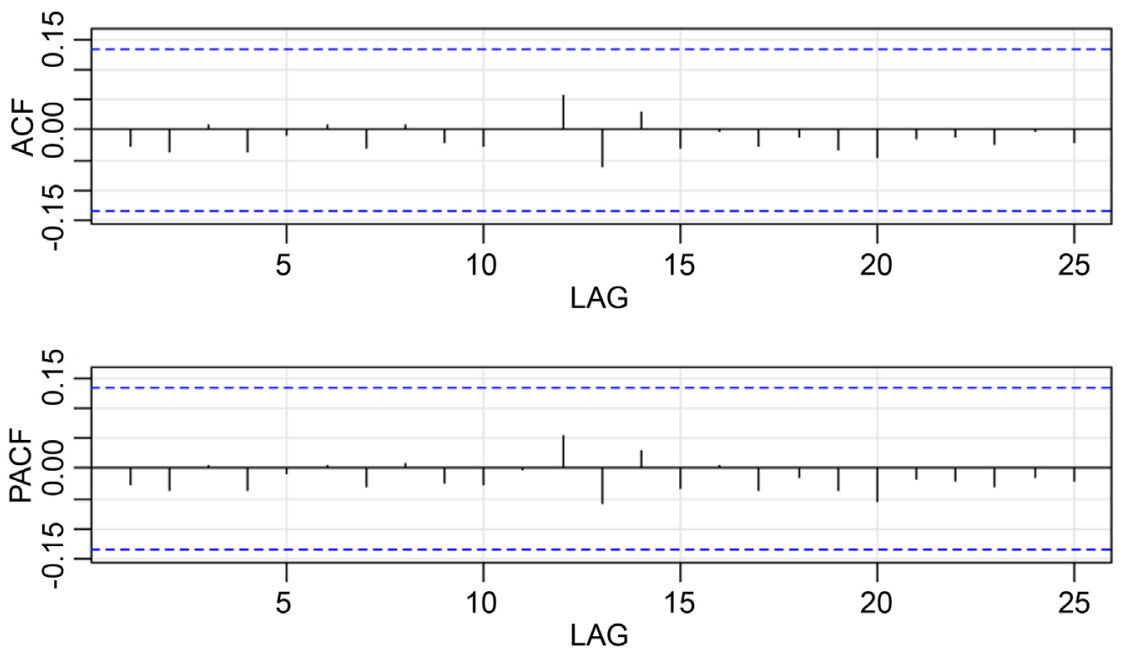

Figure 8. AFC and PACF charts of the square of the standardized residuals for the $\operatorname{GARCH}(12,1)$ model.

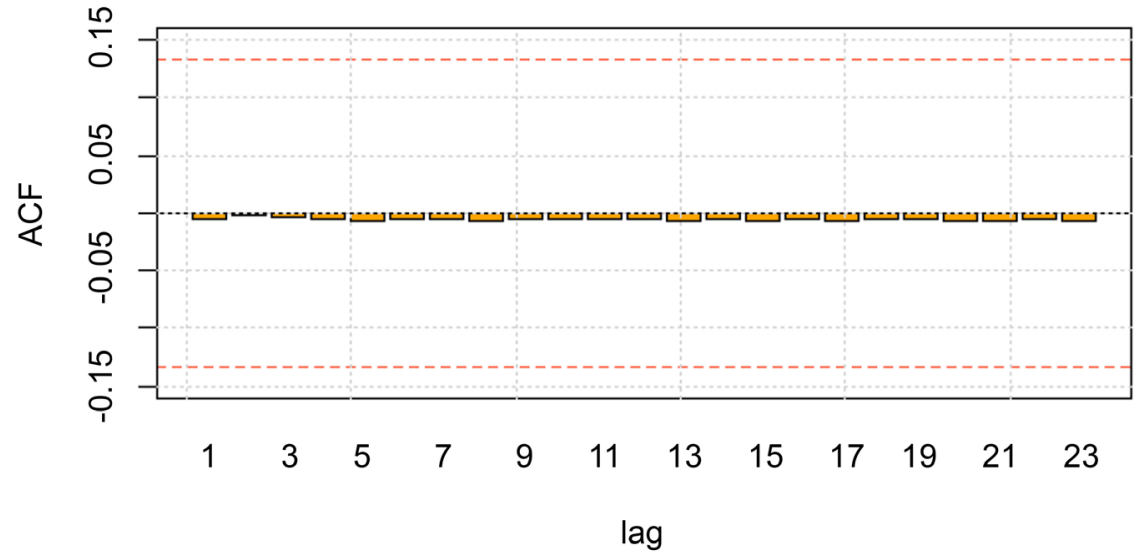

Figure 9. AFC chart of the square of the standardized residuals for the $\operatorname{EGARCH}(12,1)$ model.

Table 2. Parameter estimate, standard error, and $p$-value of the $\operatorname{ARCH}(12), \operatorname{GARCH}(12$, $1)$, and $\operatorname{EGARCH}(12,1)$ models.

\begin{tabular}{cccccccccc}
\hline & \multicolumn{3}{c}{ ARCH(12) } & \multicolumn{2}{c}{ GARCH(12, 1) } & \multicolumn{2}{c}{ EGARCH(12, 1) } \\
\hline & Est & s.e. & $p$-value & Est & s.e. & $p$-value & Est. & s.e. & $p$-value \\
\hline$\mu$ & 0.0012 & 0.0020 & 0.7053 & 0.0012 & 0.0031 & 0.6933 & -0.0068 & 0.0002 & 0.0000 \\
$\omega$ & 0.0007 & 0.0002 & 0.0001 & 0.0007 & 0.0002 & 0.0001 & -1.1825 & 0.0172 & 0.0000 \\
$\alpha_{1}$ & 0.8719 & 0.2916 & 0.0029 & 0.8719 & 0.0119 & 0.0001 & -0.2028 & 1.0702 & 0.8497 \\
$\alpha_{2}$ & 0.0001 & 0.0000 & 0.0000 & 0.0001 & 0.0000 & 0.0000 & -0.1862 & 0.9804 & 0.8494 \\
$\alpha_{3}$ & 0.0001 & 0.0000 & 0.0000 & 0.0001 & 0.0000 & 0.0000 & -0.0366 & 0.3328 & 0.9125 \\
$\alpha_{4}$ & 0.0029 & 0.0038 & 0.4469 & 0.0029 & 0.0038 & 0.4468 & 0.1366 & 0.9010 & 0.8795 \\
$\alpha_{5}$ & 0.0001 & 0.0028 & 0.9999 & 0.0001 & 0.0028 & 0.9999 & -0.6129 & 1.4908 & 0.6810 \\
$\alpha_{6}$ & 0.0001 & 0.0040 & 0.9999 & 0.0001 & 0.0040 & 0.9999 & 0.0628 & 1.1507 & 0.9565 \\
$\alpha_{7}$ & 0.0001 & 0.0000 & 0.0000 & 0.0001 & 0.0000 & 0.0000 & 0.4518 & 0.7132 & 0.5264 \\
\hline
\end{tabular}




\begin{tabular}{|c|c|c|c|c|c|c|c|c|c|}
\hline Contir & & & & & & & & & \\
\hline$\alpha_{8}$ & 0.0029 & 0.0061 & 0.6376 & 0.0029 & 0.0060 & 0.6350 & 0.1197 & 0.4016 & 0.7657 \\
\hline$\alpha_{9}$ & 0.0001 & 0.0000 & 0.0000 & 0.0001 & 0.0000 & 0.0000 & -0.1064 & 0.3412 & 0.7551 \\
\hline$\alpha_{10}$ & 0.0012 & 0.0023 & 0.5872 & 0.0012 & 0.0023 & 0.5871 & -0.2842 & 0.9506 & 0.7649 \\
\hline$\alpha_{11}$ & 0.0001 & 0.0306 & 1.0000 & 0.0001 & 0.0303 & 1.0011 & 0.0830 & 0.7530 & 0.9123 \\
\hline$\alpha_{12}$ & 0.4362 & 0.1873 & 0.0198 & 0.4362 & 0.1626 & 0.0073 & 0.3748 & 1.8671 & 0.8409 \\
\hline$\beta_{1}$ & - & - & - & 0.0001 & 0.0000 & 0.0000 & 0.8059 & 0.0002 & 0.0001 \\
\hline$\gamma_{1}$ & - & - & - & - & - & - & 0.4213 & 1.2387 & 0.7338 \\
\hline$\gamma_{2}$ & - & - & - & - & - & - & -0.378 & 0.4600 & 0.4109 \\
\hline$\gamma_{3}$ & - & - & - & - & - & - & 0.2411 & 0.8475 & 0.7760 \\
\hline$\gamma_{4}$ & - & - & - & - & - & - & -1.0571 & 2.7773 & 0.7035 \\
\hline$\gamma_{5}$ & - & - & - & - & - & - & 1.4244 & 0.1195 & 0.0000 \\
\hline$\gamma_{6}$ & - & - & - & - & - & - & -0.1117 & 0.5592 & 0.8417 \\
\hline$\gamma_{7}$ & - & - & - & - & - & - & -0.5213 & 0.5849 & 0.3728 \\
\hline$\gamma_{8}$ & - & - & - & - & - & - & 0.0240 & 0.2847 & 0.9327 \\
\hline$\gamma_{9}$ & - & - & - & - & - & - & -0.1529 & 0.1613 & 0.3432 \\
\hline$\gamma_{10}$ & - & - & - & - & - & - & 0.3374 & 0.7749 & 0.6633 \\
\hline$\gamma_{11}$ & - & - & - & - & - & - & 0.0107 & 1.3196 & 0.9935 \\
\hline$\gamma_{12}$ & - & - & - & - & - & - & -0.2610 & 3.1678 & 0.9343 \\
\hline$\theta$ & - & - & - & - & - & - & 3.3948 & 1.3887 & 0.0145 \\
\hline Test & & 0.9997 & & & 0.9997 & & & 0.9997 & \\
\hline
\end{tabular}

were not encountered in the EGARCH since Geweke [29] and Milhoj [30] proposed the $\log \mathrm{ARCH}$ model in order to avoid the negative estimates. These findings, using the Ghana's inflation data, suggest that the $\operatorname{EGARCH}(12,1)$ is ultimately the best fitting model.

Figure 10 displays plots of the square residuals (blue line) and that of the conditional variance (green line). These lines have sort of typical garch-type pattern. A period of large volatility can be observed where the green line goes up and residuals tend to be larger with the most notable period around 31 and 50.

Figure 11 displays time series forecasts of volatility in inflation rates using the EGARCH model fit. This figure displays the time series forecast of volatility in inflation rates for the next 12 months (from January 2018 to December 2018). The inflation rate forecast gives an indication that, in 2018, general prices of goods and services are likely to increase. These forecasts suggest Ghana's economy is likely to be slightly unstable in 2018 and beyond. This is confirmed by the plot of the impact of volatility in Figure 12. This figure suggests that we are forecasting increasing volatility in 2018 with the highest inflation rate of $10.4 \%$ in January 2018 and the lowest inflation rate of 9.3\% in November 2018. At the time of writing this paper, inflation figure for December has not been reported by the GSS. 


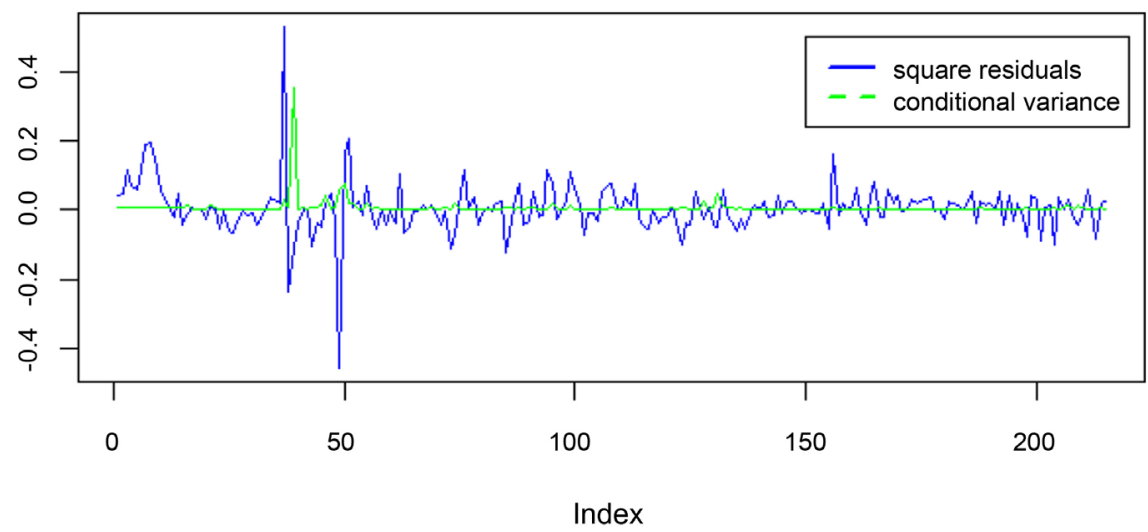

Figure 10. Plots of the estimated square residuals (blue line) and the conditional variance (green line).
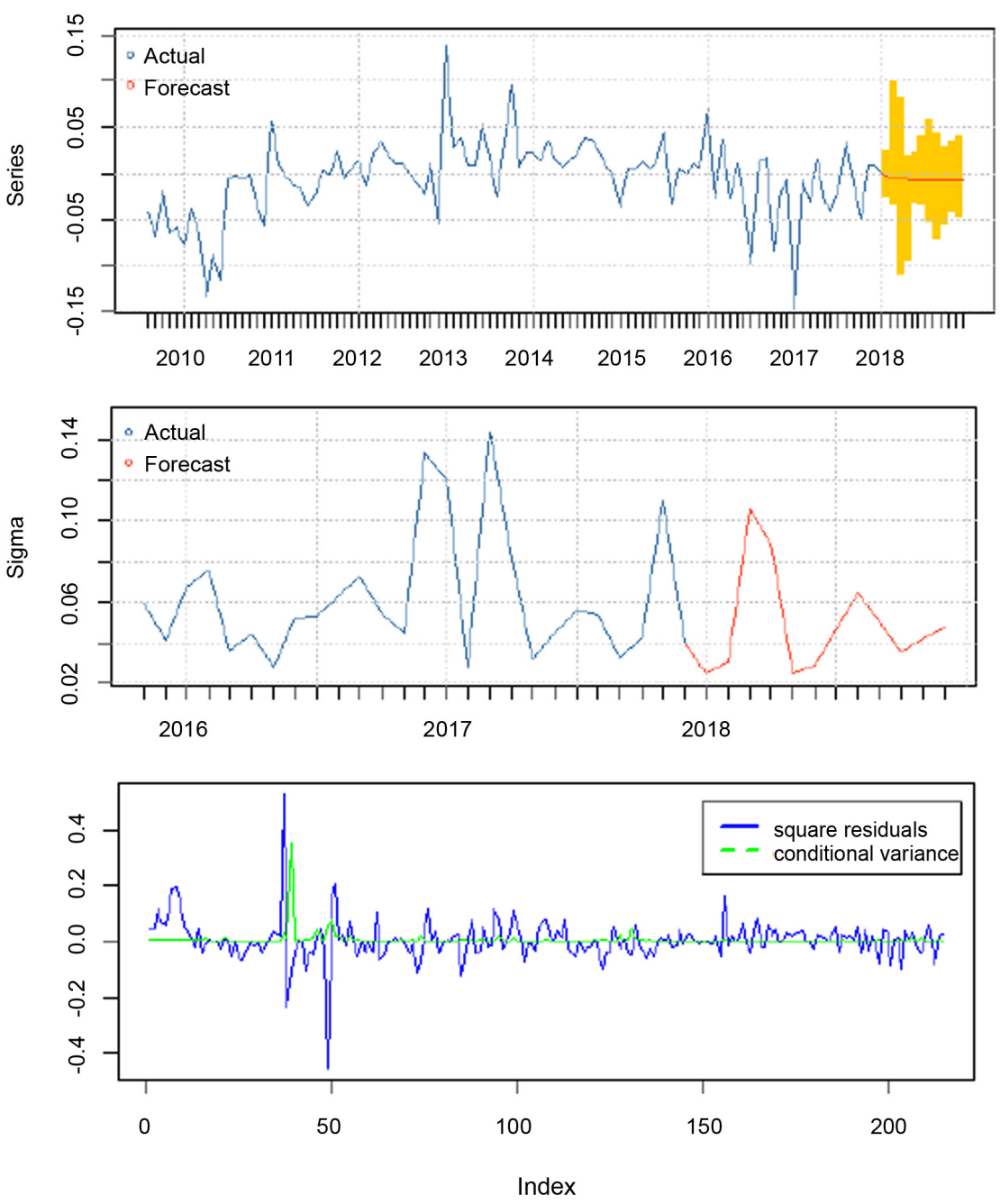

Figure 11. Time series forecasts (red line) of volatility in inflation rates for 2018.

It is important to note that volatility for 2018 is relatively lower with a general decrease in inflation rates. This predicted volatility in the 2018 inflation rates is confirmed in Figure 13 for the 2018 inflation rates. 


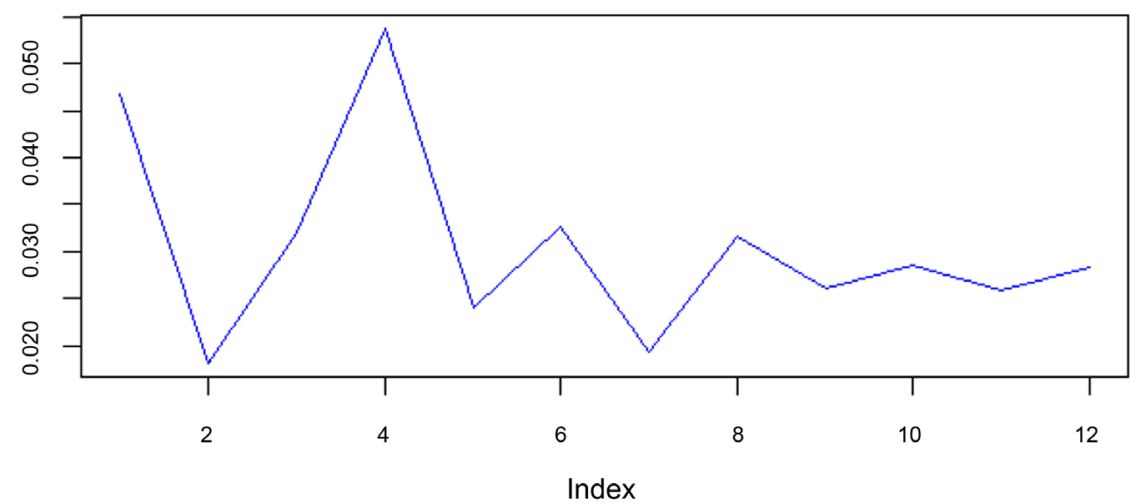

Figure 12. Plot of the impact of volatility in inflation rates for 2018.

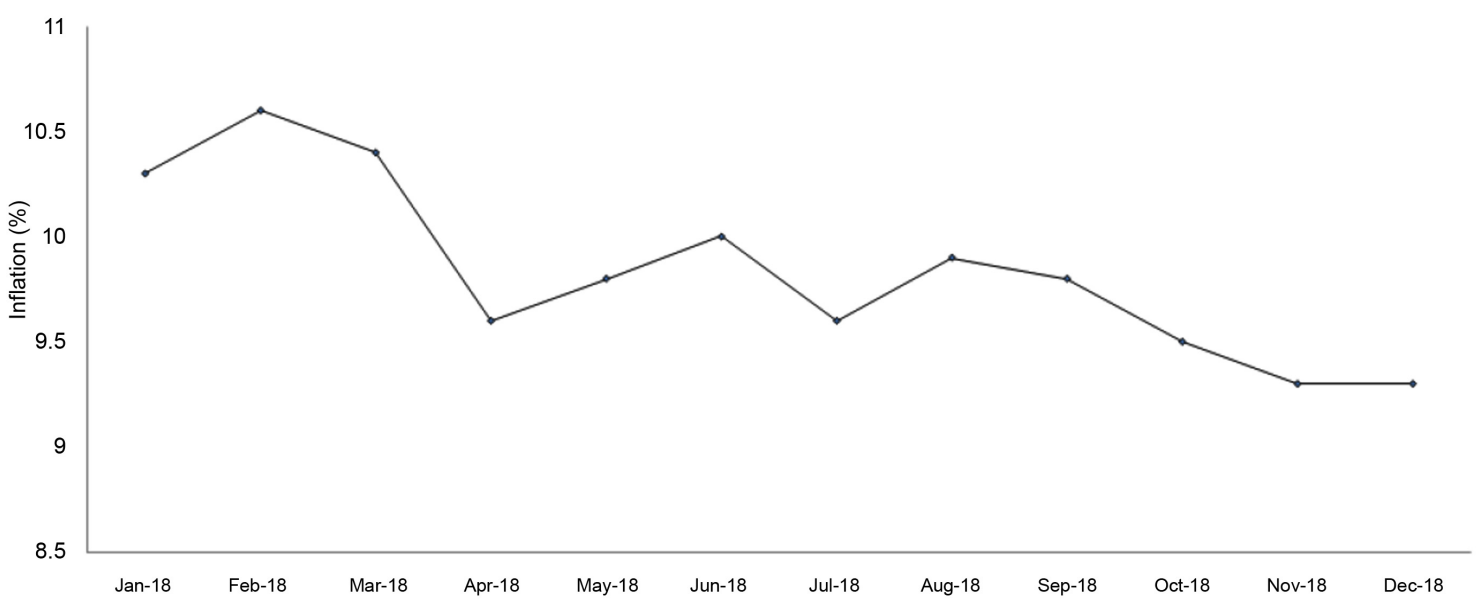

Figure 13. Time series plot of inflation rates for 2018 .

We also used the 2000 to 2018 inflation rates to forecast volatility for 2019 . Figure 14 displays time series forecasts of volatility in inflation rates using the EGARCH model fit. This figure displays the time series forecast of volatility in inflation rates for the next 12 months (from January 2019 to December 2019). The inflation rate forecast gives an indication that, in 2019, general prices of goods and services are likely to increase. These forecasts suggest Ghana's economy is likely to be slightly unstable in 2018 and beyond. This is confirmed by the plot of the impact of volatility in Figure 15. This figure suggests that we are forecasting increasing volatility in 2019 .

\section{Discussion and Conclusions}

In this paper, we modeled Ghana's inflation volatility and provided projections of inflation volatility for 2019. That inflation rates data were obtained from the Ghana Statistical Service. These data consist of monthly inflation data from 2000 to 2018. The inflation volatility in these datasets was modeled and explained using the auto-regressive conditionally heteroskedasticity $(\mathrm{ARCH})$, generalized ARCH (GARCH), and the exponential GARCH (EGARCH) models. These models were implemented in $\mathrm{R}$ software using fGARCH package. Results from these 


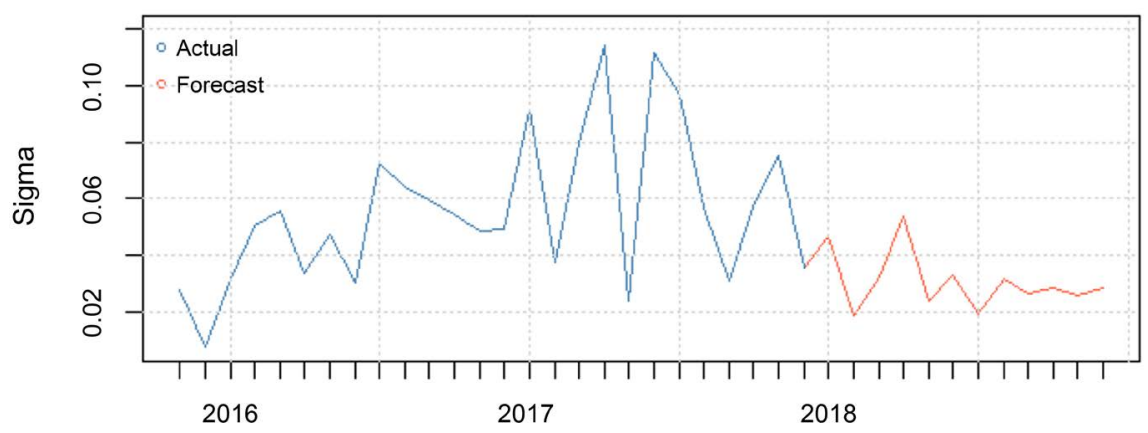

Figure 14. Time series forecasts (red line) of volatility in inflation rates for 2019.

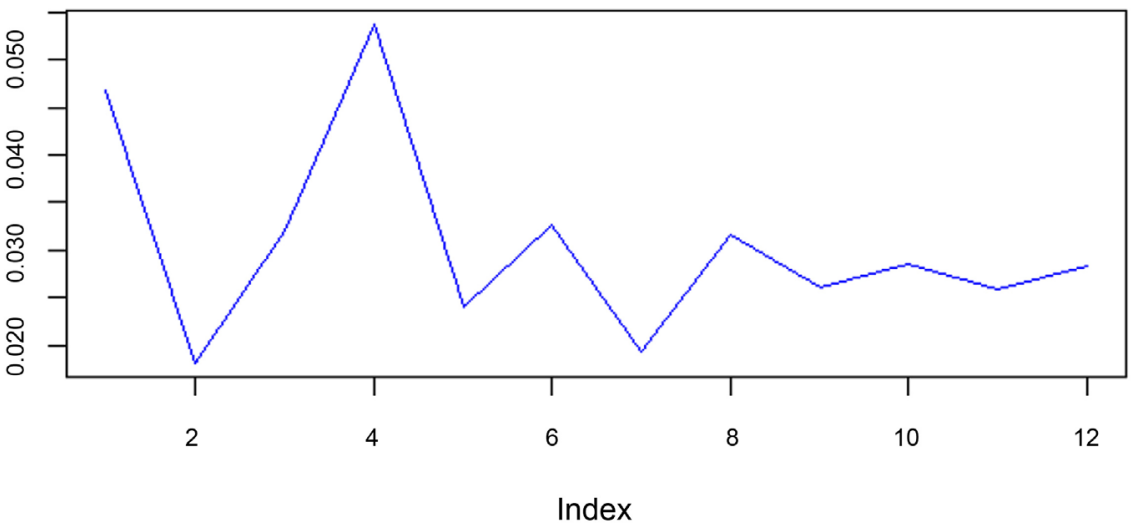

Figure 15. Plot of the impact of volatility in inflation rates for 2019.

models were then compared and best model selected using their respective AICs and log-likelihoods $(-2 \ell)$.

We observed from the results of the analyses that some of the parameter estimates and their corresponding standard errors are approximately zeros, especially in the ARCH and GARCH models. This is because higher order $q=12$ is required to eliminate auto-correlation in the residuals and restrictions imposed on the parameters in the ARCH and GARCH models results in issue of convergence as some of the diagonals of the matrix of these parameters are negatives. These results are in line with various authors [8] [10] [29] [30] who noted that the estimates from these models are most often negatives. However, these issues were not encountered in the EGARCH since Geweke [29] and [30] proposed the $\log$ ARCH model in order to avoid the negative estimates. These findings, using Ghana's inflation data, suggest that the $\operatorname{EGARCH}(12,1)$ is ultimately the best fitting model.

The proposed best fitting model, in this paper, is then used to forecasts volatility in inflation rates from January 2018 to December 2018. The inflation rates forecast gives an indication that, in 2018, general prices of goods and services are likely to increase. These forecasts suggest that Ghana's economy is likely to be slightly unstable in 2018 and beyond. Our forecast results suggest that we are forecasting increasing volatility in 2018 with the highest inflation rate of $10.4 \%$ in January 2018 and the lowest inflation rate of 9.3\% in November 2018. At the 
time of writing this paper, inflation figure for December has not been reported by the GSS. It is important to note that volatility for 2018 is relatively lower with a general decrease in inflation rates. Our analyses also revealed the possibility of increasing volatility in 2019.

Per the results presented in this paper, we therefore advise the government of Ghana to put in measures such as, monetary, fiscal, and price-control policies, to combat this anticipated rise in the inflation rates.

\section{Declaration}

\section{Acknowledgements}

The author would like to thank the Ghana Statistical Service for making data available for this study.

\section{Funding}

This study receives no funding.

\section{Disclosure Statement}

The author declares that they have no competing interests.

\section{Notes on Contributor(s)}

AI carried out the literature review and statistical analyses. AI, DO, IWA, and SA interpreted results and proof-read the manuscript. All authors have read and approved the final version of the manuscript.

\section{Consent to Publish}

Not applicable.

\section{Ethics Approval (and Consent to Participate)}

Not applicable.

\section{Availability of Data and Materials}

We do not have permission to distribute the data.

\section{Conflicts of Interest}

The authors declare no conflicts of interest regarding the publication of this paper.

\section{References}

[1] Webster, N., McKechnie, J.L., et al. (1983) Webster's New Universal Unabridged Dictionary. Dorset \& Baber, Riverside, NJ.

[2] Hall, R.E. (1982) Introduction to "Inflation: Causes and Effects". In: Inflation: Causes and Effects, National Bureau of Economic Research, Inc., MA, 1-10.

[3] Hendry, D.F. (2001) Modelling UK Inflation, 1875-1991. Journal of Applied Eco- 
nometrics, 16, 255-275. https://doi.org/10.1002/jae.615

[4] Nortey, E.N.N., Mbeah-Baiden, B., Dasah, J.B. and Mettle, F.O. (2014) Modelling Rates of Inflation in Ghana: An Application of Arch Models. Current Research Journal of Economic Theory, 6, 16-21. https://doi.org/10.19026/crjet.6.5532

[5] Chinomona, A. (2010) Time Series Modelling with Application to South African Inflation data. Master's Thesis, University of KwaZulu-Natal, KwaZulu-Natal, South Africa.

[6] Engle, R.F. (1982) Autoregressive Conditional Heteroscedasticity with Estimates of the Variance of United Kingdom Inflation. Econometrica, 50, 987-1007.

https://doi.org/10.2307/1912773

[7] Engle. R.F. (1983) Estimates of the Variance of U.S. Inflation Based Upon the ARCH Model. Journal of Money, Credit and Banking, 15, 286-301. https://doi.org/10.2307/1992480

[8] Bera, A.K. and Higgins, M.L. (1993) ARCH Model: Properties, Estimation and Testing. Journal of Economic Surveys, 7, 305-366. https://doi.org/10.1111/j.1467-6419.1993.tb00170.x

[9] Bollerslev, T. (1986) Generalized Autoregressive Conditional Heteroskedasticity. Journal of Econometrics, 31, 307-327. https://doi.org/10.1016/0304-4076(86)90063-1

[10] Nelson, D.B. (1991) Conditional Heteroskedasticity in Asset Returns: A New Approach. Econometrica, 59, 347-370.

https://doi.org/10.2307/2938260

[11] Abledu, G.K. and Agbodah, K. (2012) Stochastic Forecasting and Modeling of Volatility of Oil Prices in Ghana Using ARIMA Time Series Model. European Journal of Business and Management, 4, 122-131.

[12] Suleman, N. and Sarpong, S. (2012) Empirical Approach to Modelling and Forecasting Inflation in Ghana. Journal of Economic Theory, 4, 83-87.

[13] de Brouwer, G. and Ericsson, N.R. (1998) Modeling Inflation in Australia. Journal of Business \& Economic Statistics, 16, 433-449. https://doi.org/10.1080/07350015.1998.10524783

[14] Diouf, M.A. (2007) Modeling Inflation for Mali. Volume 2007. International Monetary Fund. https://doi.org/10.5089/9781451868586.001

[15] Vizek, M. and Broz, T. (2009) Modeling Inflation in Croatia. Emerging Markets Finance and Trade, 45, 87-98. https://doi.org/10.2753/REE1540-496X450606

[16] Stock, J.H. and Watson, M.W. (2010) Modeling Inflation after the Crisis. Technical Report, National Bureau of Economic Research.

[17] R Core Team, et al. (2013) R: A Language and Environment for Statistical Computing.

[18] R Core Team, et al. (2014) R: A Language and Environment for Statistical Computing.

[19] R Core Team (2016) Vienna: R Foundation for Statistical Computing. 2016. R: A Language and Environment for Statistical Computing.

[20] Royston, P. (1993) A Pocket-Calculator Algorithm for the Shapiro-Francia Test for Non-Normality: An Application to Medicine. Statistics in Medicine, 12, 181-184. https://doi.org/10.1002/sim.4780120209

[21] Thode, H.C. (2002) Testing for Normality. CRC Press, Boca Raton, FL. https://doi.org/10.1201/9780203910894 
[22] Dickey, D.A. and Fuller, W.A. (1979) Distribution of the Estimators for Autoregressive Time Series with a Unit Root. Journal of the American Statistical Association, 74, 427-431. https://doi.org/10.1080/01621459.1979.10482531

[23] Said, S.E. and Dickey, D.A. (1984) Testing for Unit Roots in Autoregressive-Moving Average Models of Unknown Order. Biometrika, 71, 599-607. https://doi.org/10.1093/biomet/71.3.599

[24] Kwiatkowski, D., Phillips, P.C.B., Schmidt, P. and Shin, Y.C. (1992) Testing the Null Hypothesis of Stationarity against the Alternative of a Unit Root: How Sure Are We that Economic Time Series Have a Unit Root? Journal of Econometrics, 54, 159-178. https://doi.org/10.1016/0304-4076(92)90104-Y

[25] Becker, R. (2018) The New S Language. CRC Press, Boca Raton, FL.

[26] French, K.R., Schwert, G.W. and Stambaugh, R.F. (1987) Expected Stock Returns and Volatility. Journal of Financial Economics, 19, 3-29. https://doi.org/10.1016/0304-405X(87)90026-2

[27] Engle III, R.F., Ito, T. and Lin, W.-L. (1988) Meteor Showers or Heat Waves? Heteroskedastic Intra-Daily Volatility in the Foreign Exchange Market. Econometrica, 58, 525-542.

[28] Baillie, R.T. and Bollerslev, T. (2002) The Message in Daily Exchange Rates: A Conditional-Variance Tale. Journal of Business \& Economic Statistics, 20, 60-68. https://doi.org/10.1198/073500102753410390

[29] Geweke, J. (1986) Exact Inference in the Inequality Constrained Normal Linear Regression Model. Journal of Applied Econometrics, 1, 127-141. https://doi.org/10.1002/jae.3950010203

[30] Milhøj, A. (1987) A Multiplicative Parameterization of ARCH Models. University of Copenhagen, Copenhagen, Denmark.

[31] Javed, F. and Mantalos, P. (2013) Garch-Type Models and Performance of Information Criteria. Communications in Statistics-Simulation and Computation, 42, 1917-1933. 